\title{
A cocktail of carcinogens from betel quid chewing
}

\author{
Sachin C. Sarode ${ }^{1} \mathbb{D} \cdot$ Gargi S. Sarode ${ }^{1}$
}

Received: 7 April 2021 / Accepted: 20 April 2021 / Published online: 25 April 2021

(c) The Author(s), under exclusive licence to Springer-Verlag GmbH Germany, part of Springer Nature 2021

We thank Oliveira et al. (2021) for their comprehensive and convincing reply to our comments (Sarode and Sarode 2021) against the paper published on 'Genetic toxicology and toxicokinetics of arecoline and related areca nut compounds: an updated review' (Oliveira et al. 2020). It is quite conceivable and acceptable that the understanding of the mode of action of a given genotoxic agent is critical to provide evidence supporting its role as a putative carcinogen. Equally important is the authors' (Oliveira et al. 2021) statement that areca nut and betel quid chewing associated carcinogenesis is a very complex toxicological issue. As clinicians and for the readers of the journal, we would like to take this opportunity to further dig deep into the complexities, which have not yet been envisaged to date in any of the scientific literature.

As reported in our previous commentary (Sarode and Sarode 2021), the areca nut alone chewing habit is very rare nowadays due to the availability of commercially and freshly prepared products. Most commonly consumed products, especially in India, are gutkha, mawa, khaini, paan masala, etc. Some of the common ingredients of these products are areca nut, tobacco, catechu, slaked lime, menthol, fennel seeds, and flavoring agents. Betel quid made with these components is placed in the oral cavity, especially in the buccal vestibule, and chewed for a longer period of time (IARC 2004). During this process of mastication, all the ingredients get mixed with each other with saliva as a base medium. This is not just a mixing of the ingredients but an amalgamation of the carcinogens occurring in the oral cavity. We prefer to call it 'a cocktail of carcinogens', which is acting on almost all parts of the oral cavity including the oropharynx and larynx (in swallowers). As the oral cavity is flooded with microorganisms, it is quite conceivable that they (bacteria, fungi, and viruses) all become an integral part of the cocktail. This unique carcinogenesis can only occur in

Sachin C. Sarode

drsachinsarode@gmail.com

1 Department of Oral Pathology and Microbiology, Dr. D.Y. Patil Dental College and Hospital, Dr. D.Y. Patil Vidyapeeth, Sant-Tukaram Nagar, Pimpri, Pune 411018, India the oral cavity and no other body organ is subjected to this level of complexity in terms of pathogenesis. To the best of our knowledge, no one has envisaged the complexity of 'a cocktail of carcinogens' in oral squamous cell carcinoma. We agree with the authors (Oliveira et al. 2021) that alkaloids and other compounds along with different arecoline metabolites and nitrosation products were identified in the saliva of consumers. But some key pivotal questions arise because of the proposed viewpoint of 'a cocktail of carcinogens'. Whether carcinogens react with each other in the cocktail? Whether the reaction is synergistic, additive, or neutralizing? Whether salivary enzymes modulate the carcinogenic potency of the cocktail? What are the bacterial and their metabolic products' role in the cocktail?

At the outset, we conclude that there is a dire need to find out the most carcinogenically active compound in the cocktail by proper extraction and detection methods. Second, there is a grave need to incorporate the "carcinogen cocktail' concept into all types of study designs meant to study carcinogens and their toxicity. This can only be achieved through the development of an appropriate disease model for all types of preclinical and in-vitro studies. Although these complexities are clinicians' viewpoints, preclinical perspectives are highly welcome to further bring refinement and understanding of betel quid carcinogenesis.

Funding This research received no specific grant from any funding agency in the public, commercial, or not-for-profit sectors.

\section{Declarations}

Conflict of interest All the authors associated with the present manuscript declared no potential conflict of interest concerning research, authorship, and/or publication of this article. 


\section{Reference}

IARC Working Group on the Evaluation of Carcinogenic Risks to Humans (2004) Betel-quid and areca-nut chewing and some areca-nut derived nitrosamines. IARC Monogr Eval Carcinog Risks Hum 85:1-334

Oliveira NG, Ramos DL, Dinis-Oliveira RJ (2020) Genetic toxicology and toxicokinetics of arecoline and related areca nut compounds: an updated review. Arch Toxicol. https://doi.org/10.1007/s00204020-02926-9 (Epub ahead of print. PMID: 33097969)

Oliveira NG, Ramos DL, Dinis-Oliveira RJ (2021) Reply to the Commentary by Sarode and Sarode on "Genetic toxicology and toxicokinetics of arecoline and related areca nut compounds: an updated review". Arch Toxicol (In press). https://doi.org/10.1007/ s00204-021-03039-7

Sarode SC, Sarode GS (2021) Comment on "Genetic toxicology and toxicokinetics of arecoline and related areca nut compounds: an updated review. Arch Toxicol. https://doi.org/10.1007/ s00204-021-03027-x

Publisher's Note Springer Nature remains neutral with regard to jurisdictional claims in published maps and institutional affiliations. 